\title{
'Mixed' Narcissistic Disorders in Relation to the Splitting of the Ego in the Process of Defence
}

\author{
David Gordon Bain
}

Philosophy-Psychology and Post-Freudian Neo-Psychoanalysis, Newmarket, Ontario, Canada

Corresponding author: David Gordon Bain, Philosophy-Psychology and Post-Freudian Neo-Psychoanalysis, Newmarket, Ontario, Canada, E-mail: dgbainsky@yahoo.com

Received: Jan 25, 2016; Accepted: Jan 27, 2016; Published: Jan 31, 2016

Copyright: (๑) 2016 Bain DG. This is an open-access article distributed under the terms of the Creative Commons Attribution License, which permits unrestricted use, distribution, and reproduction in any medium, provided the original author and source are credited.

\section{Short Communication}

Let me develop this line of thought....a short one. It evolved from one of Freud's last essays, and particularly, the paragraph below.

This is perhaps my favorite paragraph ever written by Freud and it was written the year before he died, 1938 connecting psychoanalysis to both his/its past 'trauma theory' as well as to much of the future of Psychoanalysis in the form of Object Relations (Klein, Fairbairn, Winnicott, Guntrip...) and Self Psychology (Kohut). But even more spectacularly, but unrecognized and/or unmentioned by Freud, one wonders if what Freud describes below might not be the etiology of the 'splitting of the ego' into 'the ego and the id'. Certainly, if I can put a name to it, 'the narcissistic ego' would seem to be a 'conscious' extension of the unconscious workings of what Freud called from 1923 to his death 'the id'.

Certainly, there would seem to be a descriptive overlap between narcissism, hedonism, and the id or in language that Freud did not use relative to discussing narcissism 'the narcissistic ego' as a more conscious 'vicissitude' of the id.

Without further introduction, here is what I consider to be one of Freud's most astounding last printed and published paragraphs:

'Let us suppose, then, that a child's ego is under the sway of a powerful instinctual demand which it is accustomed to satisfy and that it is suddenly frightened by an experience which teaches it that the continuation of this satisfaction will result in an almost intolerable, real danger. It must now decide either to recognize the real danger, give sway to it and renounce the instinctual satisfaction, or to disavow reality and make itself believe that there is no reason for fear, so that it may be able to retain the satisfaction. Thus there is a conflict between the demand by an instinct and the prohibition of reality. But in fact, the child takes neither course; or rather he takes both simultaneously, which comes to the same thing. He replies to the conflict with two contrary reactions, both of which are valid and effective. On the one hand, with the help of certain mechanisms he rejects reality and refuses to accept any prohibition; on the other hand, in the same breath he recognizes the danger of reality takes over the fear of that danger as a pathological symptom and tries subsequently to divest himself of the fear. It must be confessed that this is a very ingenious solution of the difficulty. Both of the parties to the dispute obtain their share: the instinct is allowed to retain its satisfaction and proper respect is shown to reality. But everything has to be paid for in one way or another, and this success is achieved at the price of a rift in the ego which never heals but which increases as time goes on. The two contrary reactions to the conflict persist as the centre-point of a splitting of the ego. The whole process seems so strange to us because we take for granted the synthetic nature of the processes of the ego. But we are clearly at fault in this. The synthetic function of the ego, though it is of such extraordinary importance, is subject to particular conditions and is liable to a whole number of disturbances'.

It is based largely on Freud's articulations above, in addition to the influence of such Psychoanalytic Object Relationists as Klein, Fairbairn, Guntrip, and Transactional Analysis founder, Eric Berne, that my following line of thinking evolved in conjunction with the concept and theory of narcissism.

Narcissism can hide in unexpected places...not always the rude and crude, old, bold and cold type.... but in the 'split disorders' like in the behavior of 'pleasers' and 'appeasers' who hide their 'sweet-hearted' rebellion and aggression behind their mask their personal of a smile and a friendly face...

If we contemplate the 'birth of an approval-seeking disorder or neurosis', it is usually in the context of a child reacting to and defensively compensating against a righteous-hottempered-narcissistic father or mother (I would say usually the father). The child learns how to please and/or appease the hot-tempered parent for purposes of avoiding punishment and/or avoiding conflict.

However, two other things happen in 'the splitting of the ego in the process of defense'. One, the child 'introjects' (internalizes) the hot-tempered, righteous-narcissistic parent (the rejecting superego, object-ego, or top dog depending on your choice of labels), and in addition, a second child undergo or alter-ego 'splits off' from the 'pleasing and/or appeasing undergo'.... and, in effect, becomes the 'righteous-narcissistic undergo' ready to do battle with the rejecting narcissistic top dog. 
This aggression can take a number of sub-directions: 1 . the 'paranoid-confrontational undergo'; 2. the 'paranoid-schizoid undergo'; 3. 'the passive-aggressive undergo; and/or 4. The passive-rebellious (i.e., 'the sneaky rebel') undergo'.

Thus, we have three different ego-states interacting with each other inter-psychically which I will name 'The Bermuda Triangle' (1. dominance; 2. submission; 3. rebellion (or 1. 'alpha'; 2. 'omega'; 3. 'beta'): 1. The righteous-rejectingnarcissistic top dog; 2 . the pleasing-appeasing undergo; and 3. the righteous-rejecting-narcissistic undergo or alter-undergo.

To this we can add a fourth (4). 'nurturing top dog ego' that attempts to try to 'keep peace and harmony in the personality 'the internal therapist' in the group while the other three ego states either align with each other and/or do battle with each other.

Within the confines of the righteous-narcissistic-rejecting undergo, there are three subtypes: 1 . paranoidconfrontational; 2. paranoid-schizoid'; 3. passive-aggressive; and 4. passive-rebellious and/or narcissistic.

Within this inter-psychic context, a 'sneaky narcissist' is born and both an underdog dualism and an underdog dialecticism can usually be seen to evolve where compromise-formations can be made between the pleasing undergo and the narcissistic undergo (in the form of one of the four sub-types of undergo narcissistic aggression confrontational, schizoid, passive aggression, passive-rebellious).

Then this 'inter-psychic conflict drama' becomes 'projected' into the external world in relation to the perception of external top dog and underdog (super and undergo) objects.

Thus, under the oppression and suppression of top dog external usually parental righteous-narcissism, a 'sneakier, more mixed or mixed up breed of combined narcissist-pleaserappeaser' is often born...well, not born but 'socialized' with an underlying rebellion against this 'socialization'.

Speaking from a therapeutic point of view, I would suggest that there is a mixture of underlying narcissistic pain, shame, guilt, and anger-aggression going on here, which the therapist likely needs to address before moving on to try to help the client move from a position of 'sneaky aggression' to 'more honest, transparent aggression', and then, from there, to a more balanced form of assertiveness that is not 'transferenceladen' with either appeasement and/or aggression. 